\title{
GLOBAL BURNED AREA MAPPING FROM EUROPEAN SATELLITES: THE ESA FIRE_CCI PROJECT
}

\author{
E. Chuvieco ${ }^{\mathrm{a}}$, Christopher Sandow ${ }^{\mathrm{b}}$, K. P. Guenther ${ }^{\mathrm{c}}$, F. González-Alonso $^{\mathrm{d}}$, J.M. Pereira ${ }^{\mathrm{e}}$, O. Pérez ${ }^{\mathrm{f}}$, A.V. Bradley ${ }^{\mathrm{g}}$, M. Schultz ${ }^{\mathrm{h}}$, F. \\ Mouillot ${ }^{\mathrm{i}}$ and P. Ciais ${ }^{\mathrm{j}}$
}

\author{
${ }^{a}$ Departamento de Geografía, Universidad de Alcalá. Colegios, 2. 28801 Alcalá de Henares, Spain. \\ emilio.chuvieco@uah.es \\ ${ }^{\mathrm{b}}$ GAF AG, Arnulfstr. 197, 80634 Munich, Germany. christopher.sandow@gaf.de \\ ${ }^{\mathrm{c}}$ German Aerospace Center (DLR), German Remote Sensing Data Center (DFD), 82234 Oberpfaffenhofen, Germany. \\ Kurt.Guenther@dlr.de \\ ${ }^{\mathrm{d}}$ Centro de Investigación Forestal (CIFOR). INIA. Crta. Km7 28040. Madrid. Spain. alonso@inia.es \\ ${ }^{\mathrm{e}}$ Instituto Superior de Agronomia, Universidade Técnica de Lisboa, Tapada da Ajuda, 1349-017 Lisboa, Portugal. \\ ${ }^{\mathrm{f}}$ GMV AEROSPACE AND DEFENCE, S.A., Isaac Newton, 11, E-28760 Madrid (Spain). operez@gmv.com \\ ${ }^{g}$ Department of Geography, University of Leicester, University Road LE1 7RH. UK. avb4@leicester.ac.uk \\ ${ }^{\mathrm{h}}$ Forschungszentrum Juelich GmbH, 52425 Juelich, Germany. m.schultz@fz-juelich.de \\ ${ }^{\mathrm{i}}$ IRD,1919 Route de Mend, 34293 Montpellier Cedex 5, France. mouillot@cefe.cnrs.fr \\ ${ }^{\mathrm{j}}$ IPSL - LSCE,CEA CNRS UVSQ, 91191 Gif sur Yvette France. philippe.ciais@1sce.ipsl.fr
}

KEY WORDS: Burned Area, Climate Change, MERIS, ATSR, VEGETATION, European Space Agency

\begin{abstract}
:
The European Space Agency (ESA) Climate Change Initiative (CCI) is part of the European contribution to the Global Climate Observing System (GCOS) program. Fire disturbance is one of the Essential Climate Variables (ECV) included in the ESA CCI program. It focus on mapping burned area (BA) using European sensors (ATSR, VEGETATION and MERIS data), and in comparing the performance of the results with other existing datasets. The project aims at developing and validating algorithms to produce consistent, stable, error-characterized global BA information. The project includes as well developing algorithms to generate georeferenced and calibrated reflectances of (A)ATSR, VEGETATION and MERIS data, identifying potential sources of confusion with burned areas (clouds, smoke, cloud shadows, water, snow, topographic shadows). The final product will be a merging of BA information derived from three different sensors. The outputs will be adapted to the needs of the atmospheric and vegetation modelling communities.
\end{abstract}

\section{INTRODUCTION}

The European Space Agency (ESA) Climate Change Initiative (CCI) is part of the European contribution to the Global Climate Observing System (GCOS) program. In particular, the objective of this initiative is producing consistent and accurate time series of Essential Climate Variables (ECV), which can be used by climate, atmospheric and ecosystem scientists for their modeling efforts (Plummer, 2009). The CCI stresses the importance of improving scientific impact of data acquired by ESA sensors, while maintain close links with key science bodies and other agencies currently generating ECV data. The first call of the CCI program includes ten ECVs covering atmospheric products (ozone, greenhouse gasses, aerosols, clouds), oceanic variables (ocean colour, sea ice, height and temperature), and terrestrial (fire, glaciers, and land cover).

Biomass burning is widely recognized as one of the critical factors affecting vegetation succession and carbon budgets worldwide (Chuvieco, 2008; Thonicke et al., 2010). At regional and local scale, fires have also important socio-economic implications, both affecting lives and structures (Chuvieco et al., 2010).

At a global scale, the effects of fire on the atmospheric chemistry are one of the most complex factors to account for in the current emission models, although recent studies estimate that biomass burning is responsible for half $(3-4 \mathrm{Pg} \mathrm{C})$ of the $\mathrm{CO} 2$ released by fossil fuels consumption (Bowman et al., 2009; van der Werf et al., 2010). The available estimations are based on bottom-up approaches, which try to account for the different factors of fire-related emissions. They require accurate mapping of pre-fire biomass, of burned areas and of the amount of biomass that has been actually consumed by the fire (Seiler and Crutzen, 1980). The generation of these variables still presents high uncertainty, and therefore the estimations have a wide range of variability (van der Werf et al., 2010). The actual area affected by fires worldwide is not yet accurately known. The most recent studies based on multitemporal series of MODIS data estimate that an average area of 3.5 million $\mathrm{km} 2$ is burned every year (Giglio et al., 2010; Tansey et al., 2008), mostly in the Tropical savannas, temperate grasslands and boreal forests. Other impacts of fire on the global climate are still poorly understood, such as the direct and indirect role of aerosols, their impact on land use change and surface albedo, the relation with tropospheric ozone and the deposition of black carbon on soils (Bowman et al., 2009).

The fire_cci project aims to improve mapping of burned areas (BA) and the use of BA information in global vegetation and atmospheric models. The BA maps will be generated from European sensors: (A)ATSR, VEGETATION and MERIS data, trying to meet the GCOS ECV requirements (Global Climate Observing System (GCOS), 2009), which require consistent, stable, error-characterized global satellite data products from multi-sensor data archives. A synthetic estimation based on the three sensors will be produced for the temporal series of 1995 to 2009 for several study sites, as well as for five years of global coverage. The project will dedicate considerable effort to validate the products and interact with modellers. From a conceptual point of view, the project tries to answer the following scientific questions: What is the actual magnitude of fire impacts? How much area is burned annually worldwide?, What are the recent trends in fire activity? These questions are the basis for other aspects of global fire science, such as the 
amount of biomass actually consumed by the fires and their associated GHG emissions, the departure of current fire occurrence from natural fire regimes, the role of fire in world deforestation (REDD+), or the main factors behind fire occurrence trends, on whether they are mostly socio-economic (land-use transformation, for instance), political (fire suppression policy) or climatically related.

\section{ORGANIZATION OF THE FIRE_CCI PROJECT}

The fire-cci project is developed by a consortium of ten teams from five different European countries: University of Alcalá, CIFOR-INIA and GMV (Spain); GAF, DLR and Julich (Germany), IRD and LSCE-CEA (France), ISA (Portugal), and University of Leicester (UK). These groups cover the different specialities required for the project: Earth Observation scientists, Climate-atmospheric-vegetation modellers, and System engineers. Since the project is part of a wider framework of the CCI program, close relations have been established with the teams developing other ECVs for the program, such as aerosols, green-house gases, land cover and clouds. All ECVs projects are also connected with the Climate Modelling User Group (CMUG), which is composed by researchers of the main European climate modelling centers such as the Hadley Center, the Max Planck Institute, Meteofrance and the ECMWF. The CMUG aims to reinforce the connection of the different projects among them and with the efforts of the climate modelling community.

\section{METHODS}

\subsection{General framework}

The fire_cci project includes the following main phases (fig. 1):

- User requirement and definition of Product Specifications.

- Pre-processing: geometric and radiometric processing of input images.

- $\quad$ BA detection and merging algorithms

- Production of temporal series of BA data.

- Validation and error characterization.

- Testing BA data within climate-vegetation models.

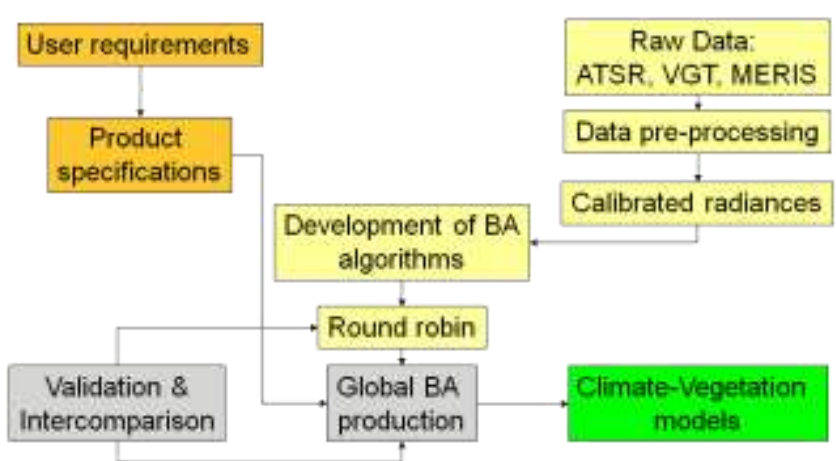

Figure 1: Modules of the fire_cci project

\subsection{User requirements and product specifications}

In order to generate a long and consistent time series of BA products, which can be used by the climate, atmospheric and ecosystem scientists for their modelling efforts, it is necessary to understand in detail their needs. For that purpose a user requirement survey was carried out, both considering the scientists potentially interested in the BA product and the literature references describing actual uses of global BA information. Forty seven scientists from different fire-related communities (modellers, remote sensing experts, natural hazards, forestry sector...) answered the questionnaire with their specific BA information needs in terms of spatial and temporal resolution, as well as formats and accuracy.

From that analysis, the product specifications (PSD) were generated, taking also into account the limitations of the input data and the CMUG and GCOS requirements. As a result of this analysis, it was compromised that the fire_cci project would include two BA products, one at pixel level, which will be the merging of the BA outputs of (A)ATSR, VEGETATION and MERIS sensors at the best potential resolution, and another one at grid level, at a 0.5 degree resolution, following the most standard climate grid modelling (CGM) size. The BA information will be provided at daily resolution, with temporal composites of 1 month for the pixel product and 15 days for the grid product. Each of the two products will be properly documented, including date of detection, confidence level and land cover for the pixel product, and sum of BA, confidence level, number of cloud-free observations, fire size distribution and dominant vegetation burned for the grid product. The BA maps will be produced in .HDF and NetcCDF formats, using the Plate Carré projection.

The target accuracy values of the BA product will be: $85 \%$ of user and producer accuracy ( $<15 \%$ of omission and commission errors, with better than $1000 \mathrm{~m}$ of geo-location accuracy, \pm 3.5 days of temporal reporting accuracy, and $15 \%$ of temporal stability.

\subsection{Pre-processing}

In terms of pre-processing, the BA products of the fire_cci project are based on level-1B and level-2 calibrated radiances from (A)ATSR, VEGETATION and MERIS. To derive corrected level 2 products advanced image geometrical matching has been applied to all sensors, using the Landsat GLS2000 as the reference source. After calibrating the three sensors, atmospheric and topographic correction based on the ATCOR algorithm (Brazile et al., 2008) has been carried out with MERIS and (A)ATSR images (VEGETATION were already provided in corrected reflectances). Water, cloud snow and cloud shadow masks have been developed to reduce the potential confusions in the BA algorithms, since these covers may present similar spectral characteristics to BA. Particularly challenging was the water mask, since water bodies may be seasonal (flooded areas), and the low radiances of water may be easily mixed up with post-fire char.

The pre-processing chain has been implemented and demonstrated on ten $500 \times 500 \mathrm{~km}$ study sites. Those sites were selected to test the BA algorithms, as they include different BA characteristics, both with high and low fire occurrence areas. They cover the major ecosystems affected by fires, as well as areas previously reported as problematic for burned area mapping (fig. 2). For those sites, the full temporal series (19952009) was processed for the sensors available in each period.

\subsection{BA algorithms}

Burned area algorithms adapted to the three target sensors and considering the diversity of burned area conditions at global scale are being developed. They will primarily aim at the ten study sites to demonstrate the consistency in the processing chain for the BA product outputs. Algorithms currently tested by the UAH-INIA and ISA teams are based on multitemporal 


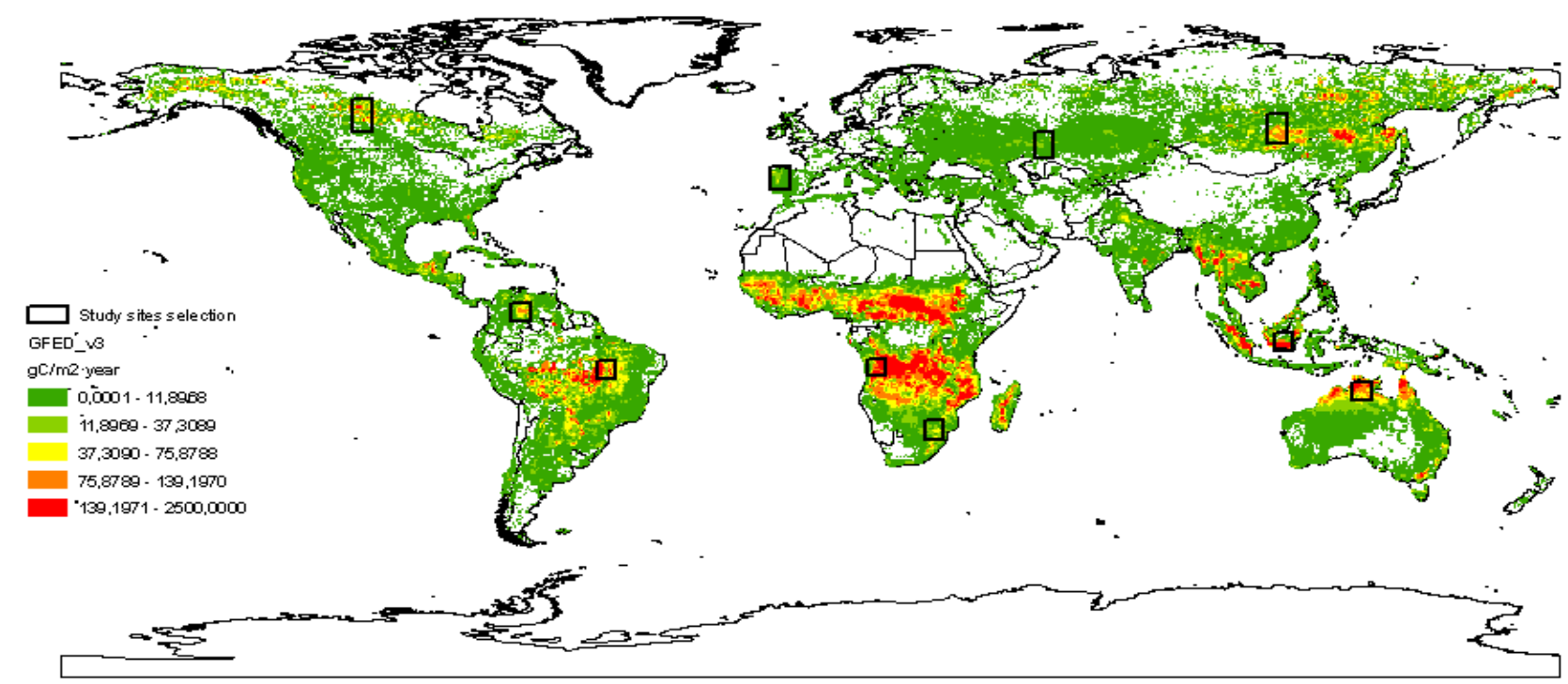

Figure 2: Study sites used for the fire_cci BA project. The estimated emissions based on the GFEDv3 (van der Werf et al., 2010) database are used as the background

change detection, contextual-regional analysis and fire seasonality.

A Round-Robin exercise was conducted between October, 2011 and January 2012 to test the most relevant existing BA algorithms, and rank their performance with the different input sensors. The goal of this exercise was to select the best performing algorithm for global production of burned area maps. The exercise was open to public participation. The same metrics used for validation were computed for each BA output. Once the best performing algorithm is selected, a merging process will be developed to create a synthetic BA product from the three BA pixel products (A-ATSR, VGT and MERIS). Finally, the complete processing chain will be applied at global scale for five selected years (1999, 2000, 2003, 2005 and 2008), to demonstrate the operational conditions of both the preprocessing and BA algorithms.

\subsection{Validation}

Validation of the BA product will be performed by comparing BA outputs with reference fire perimeters generated from Landsat-TM/ETM+ multitemporal images. A standard protocol based on the CEOS LPV recommendations was generated and agreed between the internal validation teams to extract fire perimeters from Landsat data, based on a semi-automatic algorithm (Bastarrika et al., 2011). The validation exercise will aim to measure both spatial and temporal accuracy and precision. The spatial assessment will be based on a sample of 110 multitemporal Landsat pairs acquired in 2008, while the temporal stability will be measured from a temporal series of one Landsat scene for each of the ten study sites previously commented.

Validation metrics will be based on computation of the user and producer accuracy (Congalton and Green, 1999) for each Landsat scene, as well as the consistency and temporal stability of those accuracy measurements.

\subsection{Use of BA data in models}

BA information generated by the fire_cci project will be compared with other global BA products currently available (GFED3 and MCD45), to check common trends and potential problems. Modellers within the fire_cci consortium will test the BA information in atmospheric and carbon cycle models to analyze its advantages and limitations.

\section{RESULTS}

\subsection{Pre-processing}

The fire_cci is a three year project that is currently running. The current development is focusing on the production of corrected reflectances from the three input sensors (A-ATSR, VGT and MERIS) and the generation of the BA and merging algorithms. Currently, the full temporal series of corrected reflectances (along with the water, snow and cloud masks) for all ten study sites and sensors is available for three years $(2005,2006$ and 2008), and the full time series (1995-2009) for the Australia site is being processed. This pre-processing of input data is quite critical to assure a coherent time series for BA production, but it is also very demanding in terms of computing time, including the tailoring of the global orbits to the coordinates of the study sites. The process for all sites is expected to finish in March, 2012.

\subsection{Validation datasets}

The reference fire perimeters derived from Landsat-TM/ETM+ images are ready for the temporal validation, which includes sets of Landsat pairs for 10-15 years for each study site (fig. 3). This validation dataset will be used to estimate the accuracy, consistency and temporal stability of the BA product.

Another validation dataset is being developed, which will aim to perform the spatial validation for the global product. A stratified random sampling has been performed to select representative Landsat scenes for different biomes according to the estimated fire occurrence by the MODIS BA product in 2008 .

\section{CONCLUSIONS}

The fire_cci project as part of the ESA effort to generate ECV to meet the needs of the global climate community, is trying to generate accurate, consistent and stable time series of BA information based on European sensors. The BA outputs are 


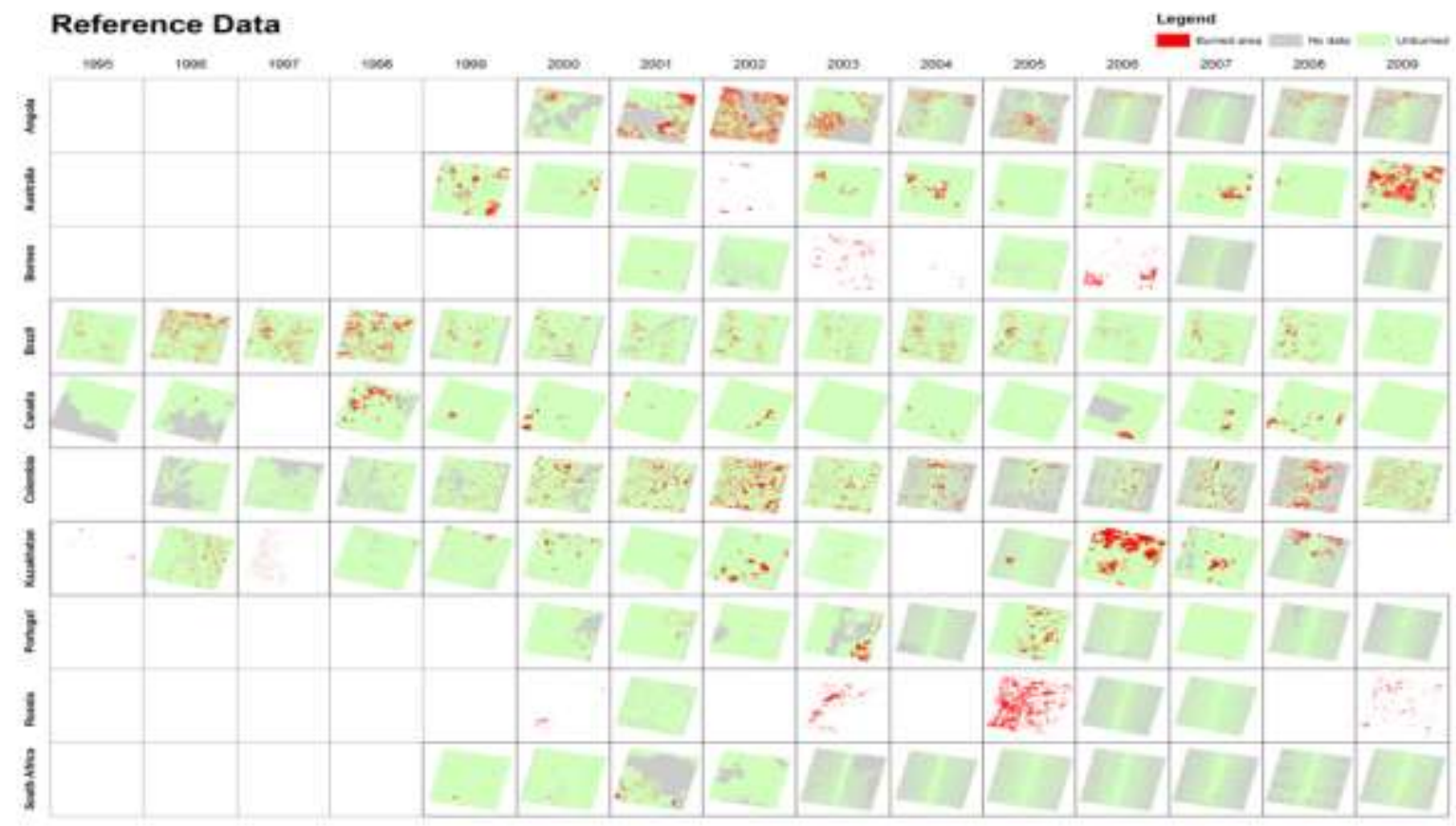

Figure 3: Time series of reference BA areas derived from multitemporal pairs of Landsat TM/ETM+ images for the study sites

adapted to the needs of the climate modelling community, both in terms of specifications and contents. The current status of the project is now focusing on developing the BA and merging algorithms and therefore, there are not yet BA outputs available.

\section{REFERENCES}

Bastarrika, A., Chuvieco, E., Martín, M.P., 2011. Mapping burned areas from Landsat TM/ETM+ data with a two-phase algorithm: balancing omission and commission errors. Remote Sensing of Environment 115, pp. 1003-1012.

Bowman, D.M.J.S., Balch, J.K., Artaxo, P., Bond, W.J., Carlson, J.M., Cochrane, M.A., D'Antonio, C.M., DeFries, R.S., Doyle, J.C., Harrison, S.P., Johnston, F.H., Keeley, J.E., Krawchuk, M.A., Kull, C.A., Marston, J.B., Moritz, M.A., Prentice, I.C., Roos, C., Scott, A., Swetnam, T., Van der Werf, G., Pyne, S.J., 2009. Fire in the Earth system. Science 324, pp. 481-484.

Brazile, J., Richter, R., Schlapfer, D., Schaepman, M.E., Itten, K.I., 2008. Cluster versus grid for operational MODTRANbased look generation of ATCOR's up tables. Parallel Computing 34, pp. 32-46.

Congalton, R.G., Green, K., 1999. Assessing the Accuracy of Remotely Sensed Data: Principles and Applications. Lewis Publishers, Boca Raton.

Chuvieco, E., 2008. Satellite observation of biomass burning: implications in global change research, in: Chuvieco, E. (Ed.), Earth Observation and Global Change. Springer, New York, pp. 109-142.

Chuvieco, E., Aguado, I., Yebra, M., Nieto, H., Salas, J., Martín, P., Vilar, L., Martínez, J., Martín, S., Ibarra, P., de la Riva, J., Baeza, J., Rodríguez, F., Molina, J.R., Herrera, M.A., Zamora, R., 2010. Development of a framework for fire risk assessment using remote sensing and geographic information system technologies. Ecological Modelling 221, pp. 46-58.

Giglio, L., Randerson, J.T., van der Werf, G.R., Kasibhatla, P.S., Collatz, G.J., Morton, D.C., DeFries, R.S., 2010. Assessing variability and long-term trends in burned area by merging multiple satellite fire products. Biogeosciences Discuss. 7, pp. 1171-1186, doi:1110.5194/bg-1177-1171-2010,.

Global Climate Observing System (GCOS), 2009. Guidelines for the generation of satellite-based datasets and products meeting GCOS requirements. World Meteorological Organization, Geneva.

Plummer, S., 2009. The ESA Climate Change Initiative. Description. ESA-ESRIN, Frascati.

Seiler, W., Crutzen, P.J., 1980. Estimates of gross and net fluxes of carbon between the biosphere and the atmosphere from biomass burning. Climatic Change 2, pp. 207-247.

Tansey, K., Grégoire, J.M., Defourny, P., Leigh, R., Peckel, J.F., Bogaert, E.V., Bartholome, J.E., 2008. A new, global, multi-annual (2000-2007) burnt area product at $1 \mathrm{~km}$ resolution. Geophysical Research Letters 35, L01401, doi:10.1029/2007GL03156.

Thonicke, K., Spessa, A., Prentice, I.C., Harrison, S.P., Dong, L., Carmona-Moreno, C., 2010. The influence of vegetation, fire spread and fire behaviour on biomass burning and trace gas emissions: results from a process-based model,. Biogeosciences Discuss. 7, pp. 697-743.

van der Werf, G.R., Randerson, J.T., Giglio, L., Collatz, G., $\mathrm{Mu}$, M., Kasibhatla, P.S., Morton, D.C., DeFries, R.S., Jin, Y., van Leeuwen, T.T., 2010. Global fire emissions and the contribution of deforestation, savanna, forest, agricultural, and peat fires (1997-2009). Atmospheric Chemistry and Physics 10, pp. 11707-11735. 